\title{
Borges e o ocultamento: apófase e paratextos oblíquos
}

\author{
Gustavo Ponciano Cunha de Oliveira*
}

\section{Resumo}

Este artigo observa como Jorge Luis Borges (1899-1986) desvia a atenção de seus leitores acerca da relação que trava com a Commedia para criar o conto "El Aleph", da coletânea homônima de 1949. A estratégia apofática, a de colocar em destaque o precursor ao não se referir a ele, segue duas vias: a ausência de referência direta ao nome de Dante Alighieri e à sua obra; os paratextos oblíquos, que nos apontam fontes - "The Cristal Egg", Hamlet e $O$ Leviatã - que funcionam como parâmetros comparativos ao Aleph enquanto objeto, a pequena esfera no porão da personagem Carlos Argentino Daneri. Atribuímos caráter crítico a paratextos de Borges, especialmente aos prefácios de História universal de la infamia (1935) e de Nueve ensayos dantescos (1949-1982). Entre os estudiosos acionados estão Genette, Hillis Miller e Thiem.

Palavras-chave: Borges; El Aleph; paratexto; apófase

\begin{abstract}
The present study analyses how Jorge Luis Borges (1899-1986) deflects his readers' attention from the connections between "El Aleph", from the eponymous collection published in 1949, and Dante's Commedia, a key text in the creation of his short story. In order to compose his text, Borges adopts an apophatic strategy, which consists in highlighting the precursor without making reference to him. This strategy uses two devices: the absence of direct reference to Dante's biography and writings in "El Aleph"; the oblique paratexts, that points out to sources - "The Crystal Egg", Hamlet and Leviathan which work as comparative parameters applicable to the Aleph only as object: the sphere at Daneri's house basement. We approach Borges's paratexts as critical texts, especially the prefaces from História universal de la infamia (1935) and Nueve ensayos dantescos (19491982). The main theoretical and critical sources are works by Genette, Hillis Miller and Thiem.
\end{abstract}

Key-Words: Borges; El Aleph; paratext; apophasis.

\section{Paratextos oblíquos}

No epílogo do livro de contos El Aleph (1949), Jorge Luis Borges (2008, p. 757758) escreve sobre a suposta origem dos motivos para suas narrativas na coletânea - uma das funções das instâncias prefacial e posfacial localizadas por Gérard Genette (1987): a

\footnotetext{
*Universidade Federal de Goiás (UFG), Goiás, Brasil. - E-mail:gponciano.co@ gmail.com

Revista Leitura V.2 nº 56 - jul/dez 2015 - Número regular - Autor/a: Gustavo Ponciano Cunha de Oliveira - p. 116 - 132.
} 
difusão da gênese. Fica evidente no epílogo a importância dispensada por Borges ao que Emir Rodriguez Monegal (1980) chama de poética da leitura ${ }^{1}$ : a criação de todas as narrativas é subordinada à relação travada com algum texto previamente escrito. As únicas variações em El Aleph (ainda assim referências a textos preexistentes) são os contos "Emma Zunz", cujo tema, garante o autor, foi-lhe presenteado por sua amiga Cecilia Ingenieros, e "Historia del guerrero e de la cautiva", baseado em eventos verídicos, argumenta Borges.

O procedimento, caro ao autor, é o mesmo exposto no prólogo à primeira edição de sua primeira coletânea de narrativas, História universal de la infamia (1935). Nele, Borges (2008, p. 341) atribui o conteúdo do livro, "ejercicios de prosa narrativa", a derivações de releituras de Stevenson, Chesterton, "de cierta biografía de Evaristo Carriego" (Borges publicara sua versão da narrativa da vida do citado poeta cinco anos antes), e dos primeiros filmes de Josef von Sternberg. Da seção "Etcétera", formada por seis narrativas curtas sobre magia que encerram a coletânea ${ }^{2}$, Borges afirma ser apenas tradutor e leitor. No corpo do texto, ao final de cada um dos seis relatos, faz a referência ao original e a seus autores: Arcana coelestia e Vera christiana religio, de Swedenborg; Libro de patrimonio, de don Juan Manuel (que, por sua vez, já acionara outro texto, o árabe As quarenta manhãs e as quarenta noites); The lake regions of Equatorial Africa, de R. F. Burton; e o Livro das mil e uma noites.

Retomemos o epílogo de El Aleph. Sobre o conto que dá nome à coletânea, o mais interessante à nossa leitura, Borges (2008, p. 758) afirma: “En 'El Zahir' y 'El Aleph' creo notar algún influjo del conto 'The Cristal Egg' (1899) de Wells”. Já as epígrafes de "El Aleph" são uma fala do protagonista de Hamlet, de William Shakespeare, e um trecho do Leviathan, de Thomas Hobbes. Estes são os paratextos que pretendemos analisar mais delicadamente.

É interessante compreender o que Genette (1987, p. 7-20) chama de paratexto para que o alcance de seu uso criativo por parte de Borges fique claro. O termo nomina a apresentação exterior de um livro (nome do autor, título), o que antecipa o texto e a suíte

\footnotetext{
${ }^{1}$ No capítulo "O leitor como escritor": "Implicitamente, Borges postula que reler, traduzir, são parte da invenção literária. E talvez que reler e traduzir são a invenção literária. Daí a necessidade implícita de uma poética da leitura" (MONEGAL, 1980, p. 91).

${ }^{2}$ Originalmente, "Etcétera" era formada por quatro narrativas. Borges acrescentou outras duas a partir da edição de 1954.
}

Revista Leitura V.2 no 56 - jul/dez 2015 - Número regular - Autor/a: Gustavo Ponciano Cunha de Oliveira - p. 116 - 132. 
oferecida ao leitor (o que vem antes e depois da coletânea de contos, antes e depois dos contos, no caso aqui observado).

Intenção e responsabilidade do autor, aponta Genette (1987), o paratexto é zona imprecisa entre o interior (o texto) e o exterior (o discurso do mundo sobre o texto), zona de transição e transação entre o texto e o fora-texto (hors-texte), uma franja, fronteira incerta, "lugar privilegiado por sua pragmática e estratégia, por sua ação sobre o público a serviço [...] de uma melhor recepção do texto e da leitura mais pertinente [...] segundo o olhar do autor e de seus aliados" (GENETTE, 1987, p. 8) $)^{3}$. É margem portadora sempre de um comentário autoral, ou mais ou menos legitimado pelo autor. Inserção externa (o oximoro resulta de sua configuração ambígua explicitada pelo prefixo para $^{4}$ ) que rodeia e prolonga o texto principal, justamente por apresentá-lo, não apenas no sentido habitual do termo: “por fazêe-lo presente, por assumir sua presença no mundo, sua 'recepção' e sua consumação, pelo menos atualmente, sob a forma de livro” (GENETTE, 1987, p. 7). É o interesse comum que reúne sob a denominação paratexto "um conjunto heteróclito de práticas e discursos de todos os tipos e épocas" (GENETTE, 1987, p. 8).

Com os prefácios, epígrafes e epílogos aqui selecionados para análise, nos deparamos com paratextos peritextuais (gêneros discursivos que circundam o texto no espaço do mesmo volume, em oposição aos epitextuais, que se situam no exterior do livro). São paratextos relativamente restritivos (destinados exclusivamente aos leitores das coletâneas de contos acionadas - mas não exclusivamente, por exemplo, a bibliófilos ou críticos literários, o que elevaria o nível de restrição) e, evidentemente, paratextos oficiais, de responsabilidade do autor do texto (os prefácios e posfácios são assinados com a recorrente sigla $J$. L. B.).

\footnotetext{
${ }^{3}$ São nossas as traduções das citações de Genette (1987).

4 “'Para' é um prefixo antitético duplo, que significa ao mesmo tempo proximidade e distância, similaridade e diferença, interioridade e exterioridade, algo que está dentro de uma economia doméstica e ao mesmo tempo fora dela, que se encontra simultaneamente deste lado de uma linha, soleira ou margem limítrofe e também além dela, equivalente em status e ao mesmo tempo secundário ou subsidiário, submisso, como um hóspede é submisso ao anfitrião, um escravo ao senhor. Além do mais, uma coisa em 'para' não está apenas, ao mesmo tempo, dos dois lados da linha limítrofe entre o dentro e o fora. Ela também é o próprio limite, a tela que é uma membrana permeável conectando o dentro e o fora. Ela confunde um com o outro, permitindo que o fora passe ao dentro, fazendo o dentro passar para fora, separando-os e juntando-os. Ela também forma uma transição ambígua entre um e outro. Embora possa parecer que determinada palavra em 'para' escolha univocamente uma dessas possibilidades, os outros significados estão sempre presentes, como uma luminosidade na palavra que a faz recusar-se a permanecer imóvel numa frase" (HILLIS MILLER, 1995, p. 13-14).
}

Revista Leitura V.2 no 56 - jul/dez 2015 - Número regular - Autor/a: Gustavo Ponciano Cunha de Oliveira - p. $116-132$. 
Observemos os paratextos acionados na leitura e como se aproximam e, mais intensamente, como se afastam do conto de Borges.

“The Crystal Egg” narra, em terceira pessoa, a história de Mr. C. Cave, dono de um antiquário, que vê um planeta misterioso no interior de um ovo de cristal quando um feixe de luz que atravessa uma falha na persiana atinge o objeto, à venda em seu estabelecimento. Mr. Cave repete algumas vezes a experiência, que lhe causa grande satisfação, mas se vê obrigado a esconder o ovo na sala que seu amigo Mr. Jacoby Wace ocupa em um hospital depois que a família tenta vendê-lo sem seu consentimento. Cave e Wace repetem a refração sob condições favoráveis a uma análise apurada pouco antes do primeiro morrer em sua loja, aparentemente durante uma nova experiência. Apesar de Wace e de outro cientista constatarem que o feixe de luz inunda estranhamente o interior do objeto, apenas Cave consegue ver o planeta, sua geografia avermelhada e seus habitantes alados. Partindo das descrições do espaço celeste do planeta feitas por Cave, Wace e o narrador chegam à conclusão de que o dono da loja de antiguidades fazia incursões pelo planeta Marte por meio de seu ovo de cristal. O narrador, em vão, vai atrás do objeto, que acabou vendido pela família Cave em um lote de relíquias para cobrir despesas com o enterro do falecido comerciante (WELLS, 1922, p. 96-117).

A epígrafe retirada de Hamlet é fragmento da cena II do segundo ato da tragédia: "Oh Deus, eu poderia viver preso numa casca de noz e me sentir rei de espaços infinitos" (SHAKESPEARE, 1995, p. 74). O trecho do Leviathan, de Hobbes, selecionado por Borges como epígrafe é aquele que fala da incompreensão da eternidade (nunc-stans) assim como a de um infinito espacial (hic-stans). "Mas dir-nos-ão que a eternidade é a manutenção do presente, o nunc-stans (como as escolas lhe chamam) que nem eles nem ninguém compreende, tal como não compreenderiam um hic-stans para uma infinita grandeza de espaço" (HOBBES, 1979, p. 390).

$\mathrm{O}$ conto "El Aleph" narra a história de 'Borges" ${ }^{5}$ em suas visitas periódicas à residência em que vivia a fonte de sua frustração sentimental, Beatriz Viterbo, iniciadas após a morte da jovem. 'Borges', meio a contragosto, começa a aproximar-se do primo de Beatriz, Carlos Argentino Daneri, com quem a jovem manteve uma relação amorosa velada.

\footnotetext{
5 Diferenciamos 'Borges' - incursão autoral na ficção - do escritor Borges por meio da aplicação de aspas simples. O mesmo procedimento, quando necessário, será tomado com outros personagens factuais transpostos ao universo literário.
}

Revista Leitura V.2 n⿳0 56 - jul/dez 2015 - Número regular - Autor/a: Gustavo Ponciano Cunha de Oliveira - p. 116 - 132. 
Conhecendo o círculo literário do qual participa o protagonista, Daneri decide apresentarlhe sua poesia, de qualidade duvidosa, com a intenção de que 'Borges' convença 'Álvaro Melián Lafinur', primo do autor portenho, a prefaciar seu livro. Após efusiva defesa de La Tierra, seu poema épico, Daneri acaba por revelar ao desafeto sua fonte inspiradora, o Aleph, ponto esférico no qual convergem todos os espaços, localizado no porão de sua casa.

A princípio, as referências presentes nos paratextos associam-se muito bem ao conto de Borges pela descrição dos objetos e ideias apresentadas: o ovo que, se vislumbrado, permite viajar a outro espaço sem de fato haver o deslocamento; a casca de noz que, apesar de diminuta, é infinitos espaços; a reflexão sobre os espaços incomensuráveis. Os dois trechos epigrafados, assim como o ovo de cristal de Wells citado no epílogo, são como que variações ao Aleph de Borges; somam-se às versões dos pontos de espaços infinitos apresentadas pelo narrador no pós-escrito de $1^{\circ}$ de março de 1943 , ao final do conto (BORGES, 2008, p. 755-756).

$\mathrm{Na}$ transparência, o que parece acontecer neste emaranhado de citações diretas e indiretas surgidas nas instâncias paratextuais é o exercício da manifestação sincera do autor acerca da leitura que impulsiona seu ato criativo: se, para Borges, autoria não é necessariamente originalidade ou propriedade exclusiva (como sugerem suas constantes remissões aos textos traduzidos, glosados, comentados, lidos, acima de tudo), nada mais justo que revelar seus precursores e textos fontes. Porém, defendemos a ideia de que o epílogo de El Aleph, ao remeter a "The Cristal Egg", e os trechos epigrafados são recursos discursivo-poéticos de difusão paratextual oblíqua ${ }^{6}$ : ao divulgar as informações sobre a gênese de seu conto no epílogo e ao emoldurar sua narrativa com suas epígrafes, Borges desvia nossa atenção da principal referência, do texto que de fato leu criativamente - de forma não passiva - para compor seu conto: a Commedia, de Dante Alighieri. Os paratextos oblíquos, deste modo, auxiliam a apófase (a via negativa), compreendida como estratégia de composição, procedimento retórico-poético de não se referir diretamente ao precursor ou a suas teses ou procedimentos estéticos acionados, o que, por fim, destaca suas presenças. O recurso apofático inclui como espaço de sua ocorrência o texto propriamente,

\footnotetext{
${ }^{6}$ Reconhecemos certo nível de redundância ao adjetivarmos paratexto com o termo oblíquo. Porém, não abrimos mão de tal exercício por reconhecermos que deve ser destacada a importância da manipulação da força ilocutória do paratexto efetuada por Borges, sobre a qual se discutirá adiante.
}

Revista Leitura V.2 no 56 - jul/dez 2015 - Número regular - Autor/a: Gustavo Ponciano Cunha de Oliveira - p. $116-132$. 
o conto "El Aleph", e não mais apenas o fora-texto, o material paratextual que circunda o texto principal - no caso em estudo, o epílogo e as epígrafes apresentadas.

Há, portanto, no exemplo observado, manipulação da força ilocutória do paratexto: Borges ultrapassa a transmissão de uma pura informação, revelação da intenção ou interpretação de seu próprio texto - funções subordinadas ao "comprometo-me a dizer a verdade"” (GENETTE, 1987, p. 16), compromisso prontamente aceito por aquele leitor que Genette (1987, p. 9) chama de dócil, “o que não é certamente o caso de todos”. O paratexto, por seu estado limítrofe, é lugar privilegiado em El Aleph: nele, a voz de seu operador (o que posfacia; o que epigrafa) pode divergir e, ainda assim, tender a coincidir com a voz do autor Borges. Esta permeabilidade é fundamental para o trabalho oblíquo e apofático que analisamos.

“The Crystal Egg” e os dois fragmentos em epígrafe servem, como já afirmado, apenas pontualmente como parâmetros comparativos à pequena circunferência que é o Aleph; ao observar os contextos em que esses objetos surgem em seus respectivos primeiros textos e o que eles trazem à sua reflexão, constata-se uma completa inadequação quanto ao ideário associado a eles e ao que é associado à paradoxal circunferência no conto de Borges.

$\mathrm{O}$ conto de H. G. Wells é uma fusão de mistério (de início a insatisfação e apreensão de Mr. Cave com a possível venda do ovo de cristal, superfaturado por ele ao perceber o entusiasmo de dois compradores inesperados, e a posterior briga com a família, que insiste em negociar o objeto, nos instiga o interesse por descobrir o que há de especial na peça - só no $38^{\circ}$ parágrafo, já na sala do hospital ocupada por Wace, é sugerido que o dono do antiquário tem certas visões ao observar o interior do ovo de cristal. No $39^{\circ}$, ele inicia seu relato minucioso sobre a primeira experiência com o objeto) e ficção científica (o apreço de Mr. Cave pela ciência o faz analisar e experimentar opticamente o ovo de cristal e sua singular reação à luz, evidentemente mais luminescente se o comerciante apresenta-se mais triste e fraco durante as provas). Diferentemente do Aleph de Borges, o ovo de cristal de Wells permite a seu personagem principal viajar a um único lugar: àquele ambiente vermelho onde habitam seres alados. O drama familiar e a solidão de Mr. Cave configuram o topos hostil que torna o singular objeto motivo de interesse, entusiasmo e dedicação do protagonista.

Revista Leitura V.2 no 56 - jul/dez 2015 - Número regular - Autor/a: Gustavo Ponciano Cunha de Oliveira - p. 116 - 132. 
Fazendo a remissão ao texto de Shakespeare (1995, p. 73-78), ao contexto em que o príncipe Hamlet cita a casca de noz que é infinitos espaços, no diálogo que trava com os companheiros Rosenkrantz e Guildenstern na cena II do segundo ato, fica evidente que Hamlet não analisa ou discorre sobre uma perspectiva filosófica de questionamento das ordens espacial e temporal, ou sobre o limite da linguagem diante da vastidão do que poderia vir de fato a ser por ela representado; e (a mais elementar das contestações que podemos aqui apresentar) tampouco Hamlet trata de um objeto que de fato lhe faz viajar a espaços infinitos - estas, possíveis leituras do Aleph borgiano.

O trecho de Hamlet em epígrafe ao conto de Borges é, devido à relativa facilidade da refutação anteriormente apresentada, o exemplo mais evidente, durante a leitura que realizamos, do que Compagnon (1996, p. 13-15), em sua tipologia da ação de leitura, chama de ablação: o trabalho de recorte que desloca o fragmento do texto original em um trabalho de apropriação, tornando-o autônomo por meio da leitura e, consequentemente, passível de ser enxertado em um novo texto, ao lado de outras unidades dispersas, justapostas e combinadas, possibilitando, inclusive, que signifique diversamente do que significa no contexto original. A citação, uma única fala de Hamlet - mutilada por Borges, que estrategicamente não a cita por completo ${ }^{7}$ e não usa a marca normativa da supressão, as reticências - diferentemente do que pode parecer na situação de epígrafe, é uma referência não a espaços infinitos, mas, ironicamente, à Dinamarca, a qual Hamlet avalia como sua prisão, espaço onde impera a desonestidade, o que a torna mais insignificante e minúscula para o protagonista. É exatamente o que Borges exclui da fala de Hamlet que permitiria ao leitor da epígrafe (conhecedor da trama da tragédia de Shakespeare) compreender que os espaços infinitos são inalcançáveis porque o ambiente é de corrupção, traição, homicídio e vingança.

Sobre o Leviatã, reproduzimos comentário de Renato Janine Ribeiro (2003), que, ao tentar subordinar o conto de Borges ao texto hobbesiano, revelar-se pronto a aceitar o subentendido contrato (oblíquo) de "dizer a verdade" diante do epigrafador borgiano ao mesmo tempo em que se demonstra um leitor interessado, já que não cita o fragmento de Hamlet. O efeito alcançado é o contrário de sua pretensão primeira: exclui qualquer

\footnotetext{
7 "Oh Deus, eu poderia viver preso numa casca de noz e me sentir rei de espaços infinitos, se não fossem os maus sonhos que tenho" (SHAKESPEARE, 1995, p. 74).
}

Revista Leitura V.2 n 56 - jul/dez 2015 - Número regular - Autor/a: Gustavo Ponciano Cunha de Oliveira - p. 116 - 132. 
semelhança contextual entre a esfera furta-cor no porão na casa de Daneri com o topo da montanha em Hobbes:

São de Hobbes a epígrafe e a inspiração do conto El Aleph, de Jorge Luís [sic] Borges [...]. Mas a estória do homem que se deita no chão para ver, num nó de madeira no teto, o alfa por onde passam todas as imagens do mundo e do tempo, não responde à preocupação do filósofo que deseja galgar um morro para decifrar, pela guerra civil, o que são loucura e hipocrisia; porque o Aleph não é a Montanha do Diabo. (RIBEIRO, 2003, p. 110-111n)

De fato, o Aleph não é a Montanha do Diabo hobbesiana, a metáfora para o governo concentrador de onde o monstruoso Leviatã domina todos os poderes e enfrenta, organizado, legitimado e soberano, o controle divino. O Aleph é, antes, a abordagem oblíqua de Borges sobre sua própria biografia e suas leituras. O texto primordial sobre o qual Borges aplica sua releitura específica lhe fornece um pretérito nunc-stans hic-stans: o círculo celestial no Paraíso.

\section{A biografia de Dante}

Leopoldo Bernucci (2001, p. 83-84) sugere que, ao longo de sua produção literária, "Borges se apresentou ao seu leitor debaixo de quatro máscaras ou personae". Na primeira, o nome Borges surge, em alguns poemas e contos, de forma reservada: a participação ficcional de Borges é limitada e passiva, sem que o gesto indique timidez. Alguns exemplos são "Hombre de la esquisa rosada" e "El Zahir". A projeção autoral aqui é parcial e mínima, defende Bernucci. Na segunda máscara ou modo de autoinclusão, "Borges ocupa um lugar central como protagonista ou objeto de sua representação" (p. 84), assim como ocorre em “Agosto 25, 1983", "Borges y yo" e "El Aleph”. Na terceira máscara, aponta Bernucci, Borges "se faz presente ao apagar seu nome somente para logo impor os aspectos de sua biografia facilmente reconhecíveis por nós". Um dos exemplos é “Tlön, Uqbar, Orbis Tertius". Neste conto de El jardín de senderos que se bifurcan (1941) estão, por exemplo, Adolfo Bioy Casares (amigo e parceiro de Borges); Néstor Ibarra (escritor, amigo pessoal e tradutor da obra de Borges ao francês) e Carlos Mastronardi (jornalista e escritor argentino, também amigo de Borges). Bernucci defende a ideia de que, neste caso, “o papel textual do 
narrador coincide com o papel social do autor”. Mesmo que o nome de Borges não apareça, fragmentos de uma autobiografia são reconhecíveis. A última das quatro máscaras com a qual Borges apresenta-se a seus leitores identificadas por Bernucci (2001, p. 85) é a mais sutil e tênue: a "transformação de sua voz crítica em voz ficcional, a presença incisiva do discurso ensaístico de Borges em sua ficção", como em "Examen de la obra de Herbert Quain”.

Ao tratar do conto "El Congreso" no epílogo de El libro de arena (1975), Borges (2007, p. 92) afirma ter o hábito de incluir dados biográficos em sua obra. No conto, o autor surge transfigurado na personagem narrador, Alejandro Ferri - autor de um livro intitulado Breve examen del idioma analítico de John Wilkins ${ }^{8}$, um senhor solitário que percebe estar velho diante do incontestável indício de que as novidades não mais lhe atraem pelo fato de serem meras repetições de coisas antigas com tímidas variações, sentença que, com pequenas variações, é recorrente na ensaística de Borges. Em entrevista a Vicente Zito Lema, Borges (1997, p. 45) afirmou: "Yo soy ese personaje Alejandro Ferri; aunque también es un poco Carlos Mastronardi - espero que se reconozca".

No prólogo de Nueve ensayos dantescos (1949-1982), Borges (2007, p. 413) ${ }^{9}$ escreve: "El poeta es cada un de los hombres de su mundo ficticio, es cada soplo e cada pormenor. Una de sus tareas, no la más fácil, es ocultar o disimular esa omnipresencia”. Dante é assim obrigado à árdua tarefa de ocultar sua onipresença nominando-se Dante e fazendo-se reagir, na maioria das vezes, de forma diversa da qual de fato reagiria, surpreso diante das decisões divinas, para que os leitores não o percebessem, Dante, como único juiz do tribunal da glória e da perdição em seu poema.

Bernucci (2001, p. 80) afirma que a noção autobiográfica nos textos de Borges se dá por meio de uma estratégia contraditória de ocultamento e revelação do $e u$ : Borges usa máscaras inconstantes que são dele, mas que simultaneamente são de outros. Ao depositar a questão autobiográfica entre a autoinclusão sob múltiplas máscaras e a apropriação de vida e obra alheias, Borges evidencia o que Hillis Miller (1995, p. 81) aponta como equívoco de

\footnotetext{
${ }^{8}$ O ensaio de Borges "El idioma analítico de John Wilkins” foi publicado pela primeira vez em 1942 e integra o livro Otras inquisiciones (1952).

${ }^{9}$ Em Nueve ensayos dantescos está recolhido, como prólogo, o "Estudio preliminar por Jorge Luis Borges" (1949), do volume XXXI dos Clásicos Jackson, com tradução ao espanhol da Commedia de Cayetano Rosell e notas de Narciso Bruzzi Costas.
}

Revista Leitura V.2 no 56 - jul/dez 2015 - Número regular - Autor/a: Gustavo Ponciano Cunha de Oliveira - p. 116 - 132. 
leitura, "o pressuposto de que uma obra literária pode ser explicada pela referência à individualidade criadora do autor".

A biografia é incluída por Bernucci (2001, p. 81) na lista de procedimentos em que convivem subterfúgios, máscaras, pseudônimos, falsas alusões, distorções e embustes, recorrentes em textos de Borges. A biografia serve à instabilidade do $e u$, da autoria, da personalidade. Apropriar-se ou assimilar a obra e a biografia de um outro autor para que possa compor as suas próprias é o ato de vilania (falsificação, adulteração, apropriação) elevado a elemento da poética borgiana: procedimento criativo que potencializa as qualidades destes textos porque os deslocam do estado "original". Dante torna-se melhor, Borges torna-se melhor, assim como o Quixote de Menard possibilita uma outra possível leitura do Quixote de Cervantes, ou Tom Castro de Tichborne e vice-versa (estes, em Historia universal de la infamia, obra repleta de vilões e falsificadores).

Mesmo em Autobiographical Essay (1970), o autor argentino não se aprofundou em sua vida pessoal, defende Bernucci (2001, p. 77-80). Se Borges não tem uma autobiografia propriamente dita, tem esboços dela espalhadas por seus textos, e é por meio do ocultamento em fazer-se refletido em outro que Borges se revela. A autorrevelação é lúdica e a confissão, dissimulada, afirma o pesquisador. Como poeta, e mesmo como crítico, ao escrever sobre outros autores (Whitman, Kafka, Stevenson, Coleridge, Shakespeare, Cervantes, Valéry, Wells, Joyce...) Borges simultaneamente escreve sobre si: ocultando-se neles, torna-se aparente.

Para compor "El Aleph", Borges apropria-se da obra e da biografia de Dante Alighieri, as coloca ao lado de suas próprias, em pé de igualdade; espelha no fracasso amoroso do poeta italiano, apaixonado por Beatriz Portinari, a sua intimidade e, assim como Alighieri faz em seu texto, a transpõe ao seu conto. Estela Canto (1991, p. 73), a quem o conto é dedicado, afirma que Borges, enquanto compunha "El Aleph", referiu-se a uma analogia entre eles dois e Dante e Beatriz. "Repetia-me que ele era Dante, que eu era Beatriz e que haveria de livrá-lo do inferno, embora eu não conhecesse a natureza desse inferno”. Emir Rodríguez Monegal também aponta o paralelo:

"El Aleph" es una reducción paródica de la Divina Comedia. Desde ese ángulo, "Borges" es Dante, Beatriz Viterbo es Beatrice Portinari (tan desdeñosa del poeta florentino como la argentina lo es del autor) y Carlos

Revista Leitura V.2 no 56 - jul/dez 2015 - Número regular - Autor/a: Gustavo Ponciano Cunha de Oliveira - p. $116-132$. 
Argentino Daneri es a la vez Dante y Virgilio. Su nombre Daneri es una abreviatura de Dante Alighieri; como Virgilio, es un poeta didáctico y un guía para la visión del otro mundo. (MONEGAL, 1987, p. 372 apud BERNUCCI, 2001, p. 89)

O próprio Borges, em diálogo com Antonio Carrizo, declarou que incluiu elementos autobiográficos em "El Aleph". Na entrevista, inventivamente atua no entrelugar ficção/autorreferencialidade ao afirmar que foi apaixonado por sua personagem feminina no conto, não por Estela Canto:

El Aleph creo que es un lindo cuento. El Aleph es el de punto en el espacio, en el cual está contenido todo el espacio. Y eso está tomado de la idea de la eternidad, que es un instante en el cual está contenido todo el tiempo. Yo apliqué al espacio lo que los teólogos han aplicado al tiempo. Viene a ser como una eternidad del espacio. Y luego entreveré otras cosas: había estado muy enamorado de Beatriz Viterbo; ella había muerto... En fin, puse elementos autobiográficos en ese cuento. Como hay que poner siempre, para que suenen convincente las cosas. (BORGES, 1982, p. 237)

A leitura de Bernucci aponta "El Aleph" como a representação da descida de Borges ao inferno amoroso que viveu, ao apaixonar-se por Estela Canto, e de seu sucessivo retorno - não ileso, mas diverso, talvez melhor, daquele que baixou:

Como Dante, Borges entendeu a linguagem como meio de conhecimento de si próprio e das coisas do mundo; como Dante, ele construiu um labirinto tão desproporcional e vasto para distrair-se da dor de haver perdido "Beatriz"; e, finalmente, como Dante, ele compreendeu também que nem o seu vasto conhecimento e erudição, nem a admirável literatura produzida por ele seriam suficientes para mitigar a saudosa e insuportável memória de sua amada. (BERNUCCI, 2001, p. 98-99)

Mas a descida a um Inferno não é o único dos volumes da Commedia aludido em “El Aleph”. No conto também é possível identificar uma ascensão, a elevação de 'Dante' ao Paraíso que ecoa no encontro de 'Borges' com a esfera furta-cor no porão de Daneri.

\section{Apófase}

Revista Leitura V.2 n⿳ 56 - jul/dez 2015 - Número regular - Autor/a: Gustavo Ponciano 
No prólogo de Nueve ensayos dantescos, Borges (2007, p. 409) afirma que a Commedia de Dante faz parte de um grupo de longos textos, assim como as Noites, similares a uma lâmina na qual "no hay cosa en la tierra que no esté ahí. Lo que fue, lo que es y lo que será, la historia del pasado y la del futuro, las cosas que he tenido y las que tendré, todo ello nos espera en algún lugar de ese laberinto tranquilo...". Borges acaba por confessar que fantasiou uma obra mágica que também é um microcosmo ("El Aleph", defendemos), mas diversa da Commedia, que é de âmbito universal. Tudo está no épico de Dante, afirma. Tudo também está no texto de Daneri (ou pretende ele), um poema, segundo Thiem (1988, p. 100), topográfico-enciclopédico.

'Borges' e Daneri experimentam um ponto que remete a todo o universo. Segundo Thiem (1988, p. 100-101) ${ }^{10}$, este é, em meio aos vários paralelos entre a Commedia e "El Aleph", o principal deles: "a notável similaridade entre o Deus de Dante no Paraíso e o Aleph, o ponto total de Borges". Thiem enumera as semelhanças.

No canto XXVIII do Paraíso, o peregrino 'Dante' avista Deus, um ponto em volta do qual giram nove anéis angelicais. Inicialmente, o poeta é impedido de observá-lo: "Um ponto eu vi, do qual raiava um lume: / tão forte que, por si, nos acautela / já os olhos, ao cerrá-los com seu acume” (ALIGHIERI, 1998, p. 196). No canto seguinte, 'Beatriz' afirma a 'Dante' que responderá sua questão sobre o que são os anéis que giram em torno de Deus antes mesmo que ele a formule, já que a previsão da pergunta que faria lhe foi oferecida pelo ponto "onde chega todo onde e todo quando" (ALIGHIERI, 1998, p. 201).

No canto XXX, a 'Dante' é permitido ver mais que a intensa luz divina; ele passa a divisar o núcleo em volta do qual giram os nove anéis angelicais. O ponto total, espaço paradoxal, não é apenas a concentração de todos os onde e quando: passa a ser discernível à visão humana de 'Dante', assim como o Aleph é para 'Borges' e Daneri. O ápice dessa visão é revelado no canto XXXIII, o último do Paraíso. 'Dante' afirma que "Vi recolher-se em sua mente superna / num só volume unido com amor, / o que no mundo se desencaderna” (ALIGHIERI, 1998, p. 232).

'Dante', 'Borges' e Daneri veem um ponto total similar e fazem questão de revelar isso. O “vidi” de 'Dante' na citação acima ecoa nos dois personagens de "El Aleph". Em 'Borges': “Cerré los ojos, los abrí. Entonces vi el Aleph” (BORGES, 2008, p. 752). Daneri

\footnotetext{
${ }^{10}$ São nossas as traduções das citações de Thiem (1988).

Revista Leitura V.2 n 56 - jul/dez 2015 - Número regular - Autor/a: Gustavo Ponciano Cunha de Oliveira - p. $116-132$.
} 
antecipa a descrição que 'Borges' faz do vislumbre diante do ponto total: "Al abrir los ojos, vi el Aleph" (p. 750). E já no primeiro verso de La Tierra que lê ao narrador, o poetastro sintetiza a experiência na expressão "He visto" (p. 754).

$\mathrm{O}$ que de forma substancial difere os dois primeiros personagens (transposições autorais na narrativa) de Daneri é o fato de eles reconhecerem os limites em exprimir a visão total que experimentam. Essa é uma discussão sobre os princípios e o alcance da expressão verbal artística, como defende Thiem (1988, p. 101), e, de forma mais ampla, é o questionamento do pressuposto de que "a linguagem, incluindo a linguagem literária, é primordialmente referencial, que inicialmente nomeia algum estado de coisas extralinguístico e extrai o seu valor da sua exatidão e força justamente nesse processo" (HILliS MILLER, 1995, p. 81). Ao longo de sua passagem pelo Paraíso, 'Dante' revela repetidas vezes sua incapacidade em recordar e exprimir verbalmente suas experiências diante de Deus. Compara-se ao homem que, ao despertar do sono, recorda apenas parte das maravilhas sonhadas. A lembrança das experiências no Paraíso é tão evanescente que se desfaz como a neve exposta ao sol. Aqui, a voz humana é um balbucio de criança que ainda se alimenta no seio materno. Em muitas oportunidades, o poeta peregrino lamenta, como no último canto do Paraíso: “Oh, quão curto é o dizer, e traiçoeiro, / para o conceito! Este, pra o que eu senti, / julgá-lo 'pouco’ é quase lisonjeiro”'(ALIGHIERI, 1998, p. 233). 'Borges' não tem pudor em relatar seu desespero diante da impossibilidade de expressar tudo o que divisou no Aleph, exercício já limitado pela memória, assim como ocorre a 'Dante':

Arribo, ahora, al inefable centro de mi relato; empieza, aquí, mi desesperación de escritor. Todo lenguaje es un alfabeto de símbolos cuyo ejercicio presupone un pasado que los interlocutores comparten; ¿cómo transmitir a los otros el infinito Aleph, que mi temerosa memoria apenas abarca? [...] Lo que vieron mis ojos fue simultáneo: lo que transcribiré, sucesivo, porque el lenguaje lo es. Algo, sin embargo, recogeré. (BORGES, 2008, p. 752-753)

Borges e Dante têm uma percepção em comum que os vincula, apesar dos mais de seis séculos que separam suas obras: a impossibilidade de descrever a visão que proporciona a simultaneidade do ponto total que avistam seus personagens (não é o estranho objeto descrito que torna a empresa impossível, mas o desejo de descrever todas as propriedades e detalhes de um objeto, por menor que seja). A qualidade do ponto paradoxal

Revista Leitura V.2 no 56 - jul/dez 2015 - Número regular - Autor/a: Gustavo Ponciano Cunha de Oliveira - p. 116 - 132. 
sugerida pelo narrador de "El Aleph", a inefabilidade, é digna da atenção de 'Dante' e 'Borges'. Desta percepção não compartilha Daneri. Por isso, o poetastro, à semelhança do hipotético autor da carta que, de tamanha submissão à mimesis referencial, acaba por cobrir todo o império que mapeia, prefere dedicar-se a uma minuciosa representação da geografia do planeta. Daneri é a personificação da crença na estreita referencialidade da criação artística, que se confronta com a sugestão de uma totalidade, como preferem Dante e Borges. Por maior que seja a insistência de Daneri em querer linearizá-la em sua pretensa representação total, a simultaneidade com a qual se deparam os três personagens está para além da linguagem e faz desmoronar as categorias estáveis do tempo e do espaço.

Há pontos nesta discussão que demonstram a ingenuidade poética de Daneri (uma poética de Borges em via negativa). Seu desvairamento diante da esfera no porão o impede de notar que a representação mais fiel da geografia do planeta já é limitada diante de todas as possibilidades propiciadas pelo Aleph. Há em La Tierra - sem que Daneri perceba e a coloque em prática - uma mise en abyme em potencial, a qual expõe que a referencialidade estreita e total nunca passará de sugestão, independente do esforço do poeta: se Daneri quer descrever todo o planeta, precisará descrever em seu épico o próprio poema que compõe, já que a obra está inserida no universo que pretende imitar, e ainda descrever o Aleph e todo o seu conteúdo mais uma vez. Nesta descrição, surgirão mais uma vez o poema que escreve e o Aleph, e assim sucessivamente. Se o Aleph da rua Garay não fosse destruído na demolição da casa em que vive, Daneri se aniquilaria, preso ao labirinto sem saída que não percebe ter armado contra si mesmo.

Sobre as críticas acerca da inverossimilhança da geografia dantesca na Commedia, Borges afirma:

Dante no se propuso establecer la verdadera o verosímil topografía del otro mundo. Así lo ha declarado él mismo; en la famosa epístola a Can Grande, redactada en latín, escribió que el sujeto de su Comedia es, literalmente, el estado de las almas después de la muerte y, alegóricamente, el hombre en cuanto por sus méritos o deméritos, se hace acreedor a los castigos o a las recompensas divinas. (BORGES, 2007, p. 412)

Ao dedicar o que lhe proporciona o Aleph à estreita referencialidade geográfica do planeta, Daneri perde a oportunidade de usar a arte como forma de discutir e produzir Cunha de Oliveira - p. 116 - 132. 
conhecimento acerca do íntimo humano, assim como fez Dante, de acordo com o argumento borgiano.

'Borges' e 'Dante' desesperam-se com o deleite estético da totalidade que se faz impossível no exato momento em que se manifesta. Se veem em êxtase, transportados a um extraordinário topos luminoso. Já o autor de La Tierra tenta realizar a esfera paradoxal de seu porão: exclui de seu poema qualquer menção às mais extraordinárias propriedades do Aleph, seus nunc-stans e hic-stans (aqui, uma aproximação à epígrafe de Hobbes). Em uma tentativa de domesticar o êxtase que proporciona o ponto total, Daneri também exclui de sua obra a já citada exatidão, que, de acordo com Perrone-Moisés (1998, p. 157), é "uma adequação da palavra à experiência que temos ou podemos ter das coisas”. Thiem defende a tese de que Daneri trivializa o Aleph:

Ao usar o Aleph como um tipo de máquina de videoteipe panóptica, ele [Daneri] falha por percebê-lo como um simples depósito total de imagens da vida real. Ele ignora seu verdadeiro aspecto maravilhoso: a capacidade de aniquilar os limites da percepção espacial humana, de proporcionar visualmente uma ordem transcendental do espaço. (THIEM, 1988, p. 112)

O poetastro destitui da experiência que tem com o Aleph todo o caráter de exploração dos limites do humano. Com ele, experimentar o Aleph deixa de ser uma experiência transformadora. Daneri também não apresenta a "economia sobrenatural del poema" que Borges (2007, p. 412) apreende em Dante. A idealização e a construção da Commedia são seus primeiros espetáculos. É totalizante (provida de “visão global”) porque é um cosmos: não há nada ali em vão, defende Borges. Tudo só pode manifestar sua existência na sugestão (entre totalidade e fragmento): a esfera que 'Borges' descreve ou o ponto luminoso que o peregrino 'Dante' vê no Paraíso, nunca no Aleph de Daneri, que ambiciona o polo totalizante desta relação em para. A ambiguidade da sugestão, a possibilidade de múltiplas leituras que de si permite o texto e que faz a obra perdurar nas futuras variações que já se apontam em sua leitura - aqui estão alguns dos motivos que fazem da Commedia um verdadeiro clássico para Borges.

Em “El Aleph”, a remissão mais explicita a Dante Alighieri em um termo aparece no adjetivo pedantesco (BORGES, 2008, p. 748), que 'Borges' atribui a La Tierra. Na tradução de Flávio José Cardozo, presente na edição brasileira das Obras Completas de Cunha de Oliveira - p. 116 - 132. 
Borges, o vocábulo foi substituído por "pedante” (BORGES, 1999, p. 691), apesar de o termo de origem italiana fazer parte do vocabulário brasileiro, assim como do espanhol. Nos parece que a manutenção do termo menos recorrente, como acontece na tradução de Davi Arrigucci Jr, "mixórnia pedantesca” (BORGES, 2015, p. 143), solicita mais eficazmente o leitor, o que valoriza a alusão enquanto mecanismo de referência ao autor da Commedia. Outra remissão a Dante está no sobrenome da personagem Carlos Argentino Daneri (Dante Alighieri). Interessante observar a possibilidade de Borges ter se inspirado na abreviação que é o nome do poeta italiano para dar sobrenome a seu personagem; Dante nasceu Durante Alighieri, em Florença, entre 14 de maio e 13 de junho de 1265 (LASSING, 2000, p. 15).

Segundo Jon Thiem (1988, p. 102), o fato de não haver em "El Aleph" referência explícita a Dante, "um caso de influência direta", é manifestação borgiana de que a visão total nunca passará da sugestão. A omissão aqui não é um deslize ou desejo de tomar o lugar do precursor; é proposital e expressiva. A não referência direta a Dante em meio a tantas outras citações e ecos é omissão apofática - a ausência da exposição é significante, tem efeito inverso, torna Dante e a Commedia presentes in potentia no conto de Borges. A sugestão demonstra sua eficácia ao mesmo tempo em que desmascara a necessidade da representação estreita, faz da economia seu signo de ambiguidade - é como um Aleph: "multum in parvo" (BORGES, 2008, p. 751).

Assim, o trabalho empreendido por Borges nos paratextos e no conto aqui analisados com mais atenção ultrapassa o mero jogo de enganar o leitor. Torna-se um interessante funcionamento apofático, oblíquo e alusivo que destaca seu interesse em conduzir ao extremo as conexões que os textos travam entre si, como um texto conecta-se à memória que a literatura tem de si mesma. "A literatura se escreve com a lembrança daquilo que é, daquilo que foi. Ela a exprime, movimentando sua memória e a inscrevendo nos textos por meio de um certo número de procedimentos de retomadas, de lembranças e de re-escrituras" (SAMOYAULT, 2008, p. 47). Ou mais que isso: "As obras literárias nunca são simples memórias - reescrevem as suas lembranças, influenciam os seus precursores, como diria Borges" (JENNY, 1979, p. 10). Borges explicita o que Compagnon (1996, p. 25) chama de caráter metonímico da citação, a ideia de que, ao pronunciarmos qualquer dos termos da relação leitura / escrita / releitura / reescrita, todos os outros são Cunha de Oliveira - p. $116-132$. 
simultaneamente evidenciados. É esse o trabalho ao qual se dedica Borges junto aos autores e obras que elege como os de excelência, dignos de serem chamados de tradição.

\section{Referências}

ALIGHIERI, Dante. A divina comédia: Paraíso. Trad. Italo Eugenio Mauro. Edição bilíngue. São Paulo: Ed. 34, 1998.

BORGES, Jorge Luis. Borges, el memorioso: Conversaciones de Jorge Luis Borges con Antonio Carrizo. México: Buenos Aires: Fondo de Cultura Económica, 1982. . Jorge Luis Borges y su ultimo libro: "El congreso que yo soñé". El otro Borges:

entrevistas (1960-1986). Buenos Aires: Equis, 1997. p. 39-48. Entrevista concedida a Vicente Zito Lema.

. Obras Completas I. Trad. Carlos Nejar et alii. São Paulo: Globo, 1999.

Obras Completas III. Buenos Aires: Emecé, 2007.

Obras Completas I. Buenos Aires: Emecé, 2008.

El Aleph. Trad. Davi Arrigucci Jr. São Paulo: Companhia das letras, 2015.

CANTO, Estela. Borges à contraluz. Trad. Vera M. de Campos. São Paulo: Iluminuras, 1991.

COMPAGNON, Antoine. O trabalho da citação. Trad. Cleonice Paes Barreto Mourão. Belo Horizonte: UFMG, 1996.

GENETTE, Gérard. Seuils. Paris: Seuil. 1987

HILLIS MILLER, J. A ética da leitura: Ensaios 1979-1989. Trad. Eliene Fittipaldi e Kátia Orberg. Rio de Janeiro: Imago, 1995.

HOBBES, Thomas. Leviatã. Trad. João Paulo Monteiro e Maria Beatriz Nizza da Silva. São Paulo: Abril Cultural, 1979.

JENNY, Laurent. A estratégia da forma. In:____ et alii. Poétique n. 27:

Intertextualidades. Trad. Clara Crabbé Rocha. Coimbra: Almedina, 1979. p. 5-49.

LASSING, Richard. (Org.). The Dante Encyclopedia. New York: Garland, 2000.

MONEGAL, Emir Rodríguez. Borges: uma poética da leitura. Trad. Irlemar Chiampi. São Paulo: Perspectiva, 1980.

PERRONE-MOISÉS, Leyla, Altas literaturas. São Paulo: Companhia das Letras, 1998. RIBEIRO, Renato Janine. A marca do Leviatã: linguagem e poder em Hobbes. São Paulo: Ateliê, 2003.

SAMOYAULT, Tiphaine. A intertextualidade. Trad. Sandra Nitrini. São Paulo: Aderaldo \& Rothschild, 2008

SHAKESPEARE, William. Hamlet. In: Hamlet e Macbeth. Trad. Anna Amélia Carneiro de Mendonça. Rio de Janeiro: Nova Fronteira, 1995.

THIEM, Jon. Borges, Dante, and the Poetics of Total Vision. Comparative Literature, Eugene, Oregon: University of Oregon, v. 40, n. 2, p. 97-121, 1988.

WELLS, H. G. The Crystal Egg. In: Tales of the Unexpected. London: W. Collins Sons, 1922. p. 96-117.

Revista Leitura V.2 no 56 - jul/dez 2015 - Número regular - Autor/a: Gustavo Ponciano

Cunha de Oliveira - p. $116-132$. 